\title{
Free radical generation by skeletal muscle of adult and old mice: effect of contractile activity
}

A. Vasilaki, ${ }^{3}$ A. Mansouri, ${ }^{1}$ H. Van Remmen, ${ }^{1}$ J. H. van der Meulen, ${ }^{2}$ L. Larkin, ${ }^{2}$ A. G. Richardson, ${ }^{1}$ A. McArdle, J. A. Faulkner ${ }^{2}$ and M. J. Jackson ${ }^{3}$

${ }^{1}$ University of Texas Health Center at San Antonio and Barshop Institute for Longevity and Aging Studies, San Antonio, TX 78229-3900, USA

${ }^{2}$ Institute of Gerontology, University of Michigan, Ann Arbor, MI 48109-2007, USA

${ }^{3}$ Division of Metabolic and Cellular Medicine, School of Clinical Sciences, University of Liverpool, Liverpool L69 3GA, UK

\section{Summary}

Oxidative modification of cellular components may contribute to tissue dysfunction during aging. In skeletal muscle, contractile activity increases the generation of reactive oxygen and nitrogen species (ROS). The question of whether contraction-induced ROS generation is further increased in skeletal muscle of the elderly is important since this influences recommendations on their exercise participation. Three different approaches were used to examine whether aging influences contraction-induced ROS generation. Hind limb muscles of adult and old mice underwent a 15-min period of isometric contractions and we examined ROS generation by isolated skeletal muscle mitochondria, ROS release into the muscle extracellular fluid using microdialysis techniques, and the muscle glutathione and protein thiol contents. Resting skeletal muscle of old mice compared with adult mice showed increased ROS release from isolated mitochondria, but no changes in the extracellular levels of superoxide, nitric oxide, hydrogen peroxide, hydroxyl radical activity or muscle glutathione and protein thiol contents. Skeletal muscle mitochondria isolated from both adult and old mice after contractile activity showed significant increases in hydrogen peroxide release compared with precontraction values. Contractions increased extracellular hydroxyl radical activity in adult and old mice, but had no significant effect on extracellular hydrogen peroxide or nitric oxide in either group. In adult mice only, contractile activity increased the skeletal muscle release of superoxide. A similar decrease in muscle glutathione and protein thiol contents was seen in adult and old mice

\section{Correspondence}

M. J. Jackson, Division of Metabolic and Cellular Medicine, School of Clinical Sciences, University of Liverpool, Liverpool L69 3GA, UK. Tel.: 0151706 4072; fax: 0151706 5802; e-mail: m.j.jackson@liverpool.ac.uk

Accepted for publication 11 November 2005 following contractions. Thus, contractile activity increased skeletal muscle ROS generation in both adult and old mice with no evidence for an age-related exacerbation of ROS generation.

Key words: gastrocnemius muscle; GTN; hydrogen peroxide; hydroxyl radical; microdialysis; nitric oxide; superoxide.

\section{Introduction}

Muscle wasting and loss of skeletal muscle strength are inevitable concomitants of aging and result from the loss of muscle fibers and atrophy of the remaining fibers (Porter et al., 1995). Old organisms contain increased levels of products of oxidative damage to biomolecules such as lipids, DNA and proteins (Nohl, 1993; Schoneich, 1999) and decreased levels of reductants such as glutathione (Cho et al., 2003). These changes have been attributed to an increase in generation of reactive oxygen and nitrogen species (ROS) by mitochondria in tissues of old organisms. Mitochondria from skeletal muscles of old animals contain greater amounts of damage than those from young or adult animals (Melov et al., 1995), although alternative approaches indicate that mitochondrial function in skeletal muscles of physically active old animals is unimpaired (Hansford, 1983; Rasmussen et al., 2003; Rembert et al., 2004).

An increase in ROS activity in tissues, indicated by an increase in end-point indicators of the reactions of ROS, has also been associated with exercise (Dillard et al., 1978; Davies et al., 1982; Jackson et al., 1985) and appears to be in major part due to generation by contracting skeletal muscle. The primary ROS generated by skeletal muscle during contractions are superoxide and nitric oxide (NO) with rapid dismutation of the superoxide to hydrogen peroxide (McArdle \& Jackson, 2000). Increased amounts of superoxide anion have been detected in the perfusion fluid surrounding isolated strips of diaphragm (Reid et al., 1992) and in the extracellular fluid of limb muscles (McArdle et al., 2001, 2004b) during muscle contractions. Mitochondria have also been frequently cited as the major site of superoxide generation during contractile activity (Davies et al., 1982), but recent data indicate that skeletal muscle has additional sources of generation of superoxide (McArdle et al., 2004b) that may include NAD(P)H oxidases (Javesghani et al., 2002) and other muscle plasma membrane oxidoreductases (Pattwell \& Jackson, 2004).

Skeletal muscle has well developed systems regulating ROS and preventing potentially deleterious effects of ROS, including both mitochondrial and cytosolic isoforms of superoxide dismutase (MnSOD and CUZnSOD, respectively), catalase and glutathione peroxidase enzymes and a number of direct scavengers of ROS including glutathione, vitamin $\mathrm{E}$ and ascorbate. Aging 
has been reported to be associated with an increase in the resting SOD, catalase, glutathione peroxidase and glutathione reductase activities in the muscle of aged compared with adult mice (Leeuwenburgh et al., 1994). Total glutathione levels have been reported to decrease with age in many tissues of rodents (Stio et al., 1994; Cho et al., 2003; Wang et al., 2003), but data from skeletal muscle are more variable. Leeuwenburgh et al. (1994) reported that the glutathione content of the oxidative soleus muscle increased with age in rats, but found no agerelated effect on the vastus lateralis muscle, while Bejma \& Ji (1999) similarly found no effect of age on muscle mitochondrial glutathione content.

Few publications have examined the possibility that contractile activity in muscle from old mice is associated with an increase in ROS generation in comparison with muscle from adult or young subjects, although this is an important question with implications for participation in exercise by elderly human subjects. A study by Bejma \& Li (1999) claimed that exercise produced a greater increase in intracellular ROS generation in muscle of old compared with young rats, but the techniques used by these investigators involved homogenization of tissue and may be subject to artifact due to greater iron delocalization in the aged tissue (Halliwell \& Gutteridge, 1989).

In order to clarify the relationship between the increased oxidative damage to muscle associated with aging and the ROS generation during exercise, we have examined these processes in mice prior to and following a demanding 225 isometric contraction protocol. Three distinct approaches were followed in order to obtain a comprehensive view of the process: (i) measurement of ROS generation by mitochondria isolated from skeletal muscle; (ii) analysis of ROS in muscle extracellular fluid by microdialysis techniques; (iii) determination of the muscle contents of thiols (glutathione and protein thiols). We tested the following three hypotheses: (i) At rest there would be increased ROS release from isolated skeletal muscle mitochondria of old mice associated with increased ROS in microdialysates and a decrease in muscle glutathione and protein thiols in comparison with adult mice; (ii) Following contractile activity in both adult and old mice, there would be an increased ROS release from isolated skeletal muscle mitochondria, an increase in the ROS detected in microdialysates, and a decrease in muscle thiols content compared with values at rest; (iii) Contractile activity would induce a greater ROS release from isolated skeletal muscle mitochondria, a greater increase in the ROS detected in microdialysates and a larger decrease in skeletal muscle thiols content in muscle from old mice in comparison with adult mice.

\section{Results}

Despite the lack of any significant change in body weight (adult: $29.4 \pm 1.1 \mathrm{~g}$ cf. old: $27.0 \pm 0.8 \mathrm{~g}$ ), the old ( $26-30$ months) mice had a significant reduction in the weight of several muscles compared with the adult (5-11 months) group. Gastrocnemius (GTN) (adult: $132.1 \pm 3.9 \mathrm{mg}$ cf. old: $118.4 \pm 11.7 \mathrm{mg}$; $P<0.05$ ), extensor digitorum longus (adult: $9.9 \pm 0.3 \mathrm{mg}$ vs.
Table 1 Total superoxide dismutase and catalase activities for GTN muscles of adult and old mice*

\begin{tabular}{lll}
\hline & $\begin{array}{l}\text { SOD activity } \\
\left(\mathrm{U} \mathrm{mg} \mathrm{m}^{-1} \text { protein }\right)\end{array}$ & $\begin{array}{l}\text { Catalase activity } \\
\left(\mathrm{U} \mathrm{mg}^{-1} \text { protein }\right)\end{array}$ \\
\hline Adult & $15.9 \pm 2.5$ & $6.0 \pm 1.5$ \\
Old & $17.1 \pm 1.1$ & $5.2 \pm 0.6$ \\
\hline
\end{tabular}

*There were no significant differences between values for adult and old mice.

old: $7.8 \pm 0.3 \mathrm{mg} ; P<0.05$ ), and soleus (adult $9.0 \pm 0.3 \mathrm{mg}$ vs. old $7.4 \pm 0.3 \mathrm{mg} ; P<0.05)$ muscles all showed an $18-26 \%$ decline in weight in the old mice.

\section{Effect of isometric contractions on generation of force}

The mean maximum force generated by the plantar-flexor muscles of the adult mice was $3384 \pm 183 \mathrm{mN}$ compared with $2934 \pm 374 \mathrm{mN}$ for the old mice. Despite the mean reduction in the maximum force seen in old mice the values were not significantly different. The protocol of 225 maximum isometric contractions with one contraction every $4 \mathrm{~s}$ constituted a major metabolic challenge for the muscles of mice in adult and old age groups and considerable fatigue was observed (Fig. 1). The isometric contraction protocol produced a rapid $\sim 40 \%$ loss of force during the first $2 \mathrm{~min}$ and then a more gradual $25 \%$ decline during the next $13 \mathrm{~min}$ in both adult and old mice. No significant difference in initial force production or in force production at any time was observed between the adult and old mice during the 15-min contraction protocol. For the plantarflexor muscles of both adult and old mice, the force generated at the end of the protocol was $\sim 35 \%$ of the initial force (Fig. 1).

\section{Superoxide dismutase and catalase activities of adult and old muscle}

The total superoxide dismutase (SOD) and catalase activities showed no significant differences between the muscles from adult and old mice (Table 1).

\section{ROS generation by isolated mitochondria}

The hydrogen peroxide production by isolated mitochondria is shown in Fig. 2. Data shown are mean \pm SEM for measurements from five animals. These data reflect measurements of hydrogen peroxide production in State 1 (without exogenous substrate) and show that skeletal muscle mitochondria isolated from old quiescent mice had a significantly greater rate of generation of hydrogen peroxide than mitochondria from adult mice $(P<0.05)$. Rates of hydrogen peroxide generation from skeletal muscle mitochondria isolated at the end of the contraction protocol had increased significantly for both adult and old muscle although the resulting values did not differ significantly between the adult and old groups. 
Fig. 1 Maximum forces generated by the plantarflexor group of muscles of adult $(\boldsymbol{\nabla})$ and old $(\mathbf{\square})$ mice during a demanding contraction protocol. Values for adult and old mice did not differ significantly throughout the protocol. Data are shown as the mean \pm SEM

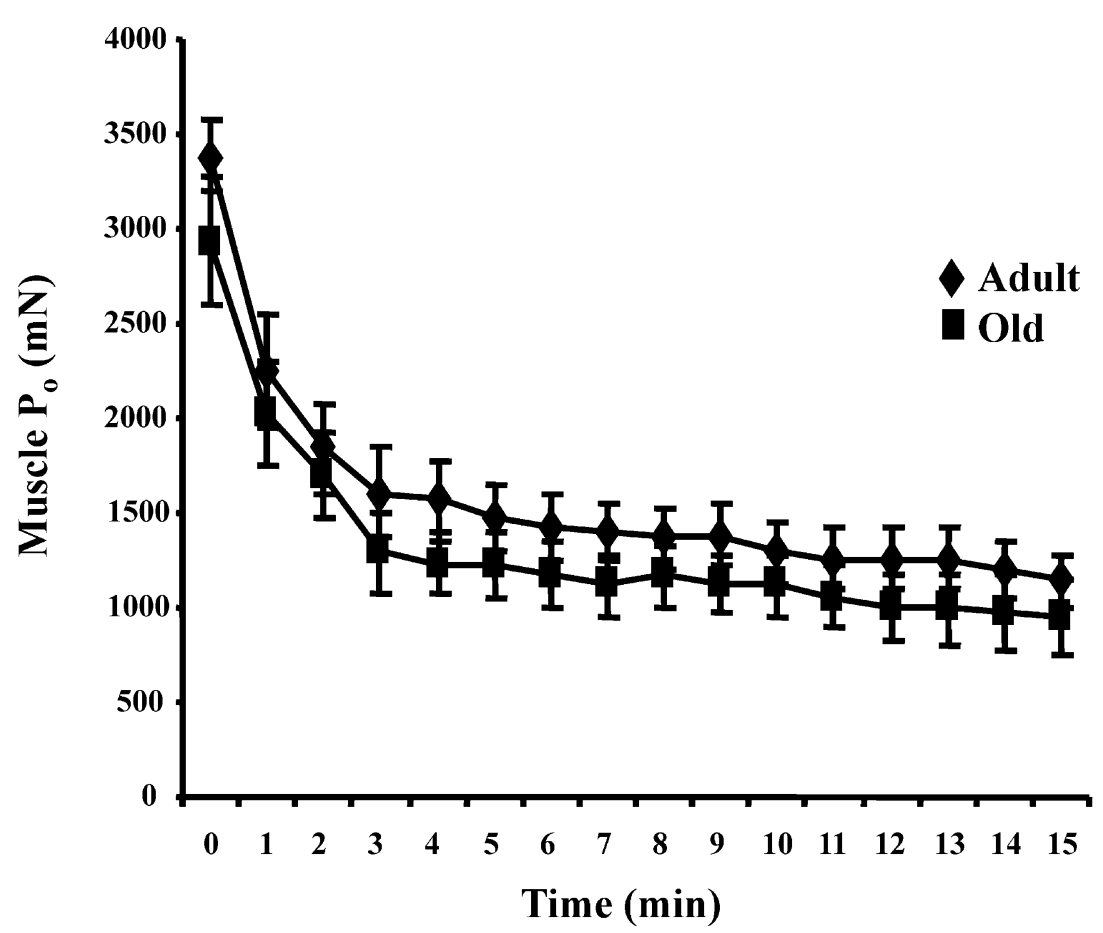

\section{Microdialysate analyses}

Each of the four ROS, superoxide, NO, hydrogen peroxide and hydroxyl radical activity, were detected in the microdialysates from GTN muscles of adult and old mice at each of the seven sampling periods before, during and after the demanding isometric protocol (Figs 3 and 4).

Baseline values of superoxide in the microdialysates from GTN muscles of old mice were unchanged compared with those from the adult mice (Fig. 3A). In the microdialysates from muscle of adult mice, the period of contractile activity was associated with a significant increase in extracellular superoxide. No significant increase in superoxide detected was seen in the microdialysates from old mice during contractions.

The total nitrate and nitrite content of the microdialysates did not differ between adult and old mice, although at each sampling period the values for muscles of adult mice were higher than those from old mice (Fig. 3B). The contraction protocol had no effect on the nitrate or nitrite content of the microdialysates from either adult or old mice.

For quiescent muscles during the first two 15-min sampling periods, the 2,3-DHB content was higher in the microdialysates of muscles from old mice than from those of adult mice (Fig. 4A), but this difference was not evident during the subsequent three 15-min baseline collections. The 15-min contraction protocol increased the formation of 2,3-DHB from salicylate for both adult and old muscles, although no significant difference existed between the two.

The hydrogen peroxide content of the microdialysates for the muscles of adult and old mice was $\sim 1.7 \mu \mathrm{M}$, with no difference between the two groups (Fig. 4B). During the period of con-

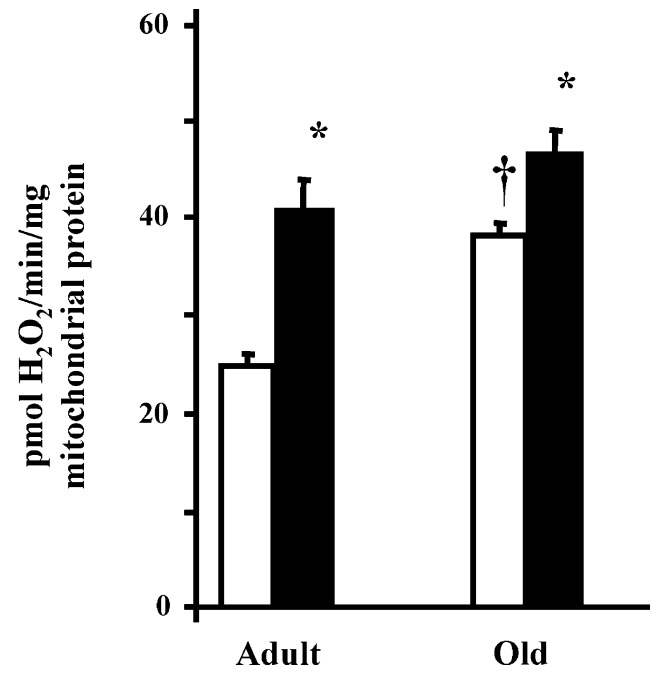

Fig. 2 Production of hydrogen peroxide by isolated skeletal muscle mitochondria prior to $(\square)$, and following $(\square)$ isometric contractions. Measurements of hydrogen peroxide production in State 1 (no added substrate) were undertaken using Amplex Red as described in the Experimental procedures section. Hydrogen peroxide production is calculated based on a standard curve generated using known concentrations of hydrogen peroxide and is expressed as pmoles hydrogen peroxide per minute per mg protein. Data shown are mean \pm SEM $(n=5)$. ${ }^{\star} P<0.05$ compared with quiescent muscle; $+P<0.05$ compared with adult mice prior to contractile activity.

tractile activity, the concentration of hydrogen peroxide tended to increase in the microdialysates of the muscles of both adult and old mice although in neither case were the increases statistically significant, nor were there any significant differences between the two groups. 
A.

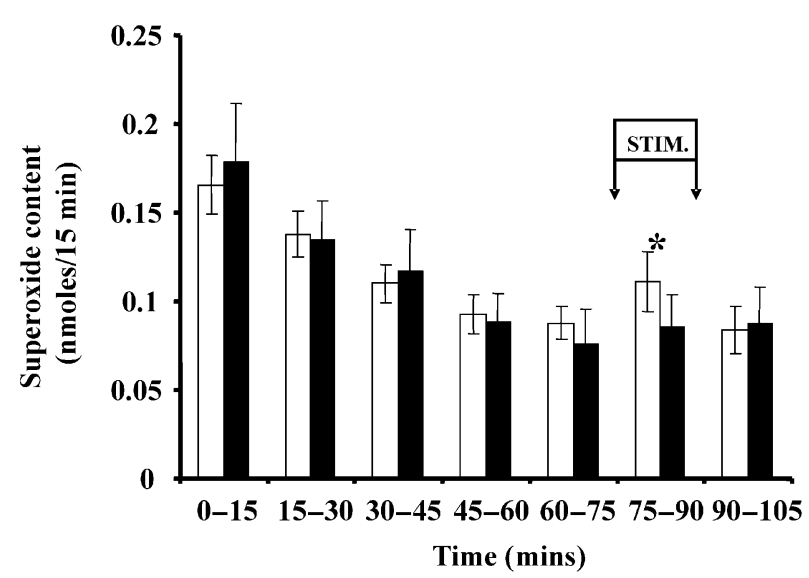

B.

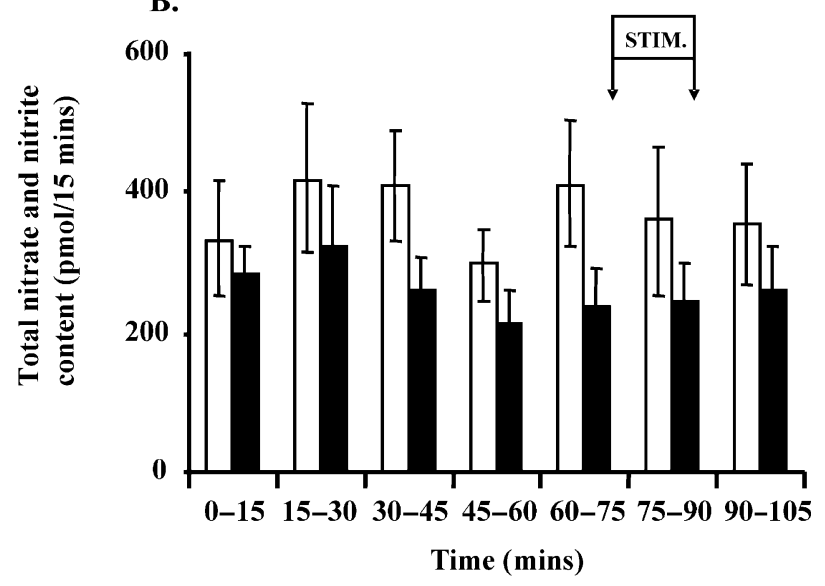

Fig. 3 The superoxide (A) and total nitrate and nitrite (B) content of microdialysates from the GTN muscles from adult $(\square)$ and old ( $\square$ ) mice. Muscles underwent 15-min periods of demanding contractile activity during the period shown. Data are shown as the mean \pm SEM. ${ }^{*} P<0.05$ compared with microdialysates from the same group of mice at the previous time point.

\section{Glutathione and protein thiol content of adult and old muscle}

The total glutathione content of the quiescent GTN muscles from adult and old mice was not significantly different (Fig. 5) and by 15 min after the contraction protocol, the total glutathione content of muscles from both groups had decreased significantly. At this time point there was no significant difference between the values from the two groups. A similar pattern of changes was seen in the muscle total protein thiol content; values for quiescent muscles did not differ between adult and old mice and both groups showed a significant decrease following contractile activity (Fig. 5B). The protein thiol contents of muscles from old mice postexercise were not significantly different to those from muscles of adult mice.

\section{Discussion}

This paper has examined whether exercise of skeletal muscle from old mice induced a greater generation of ROS compared
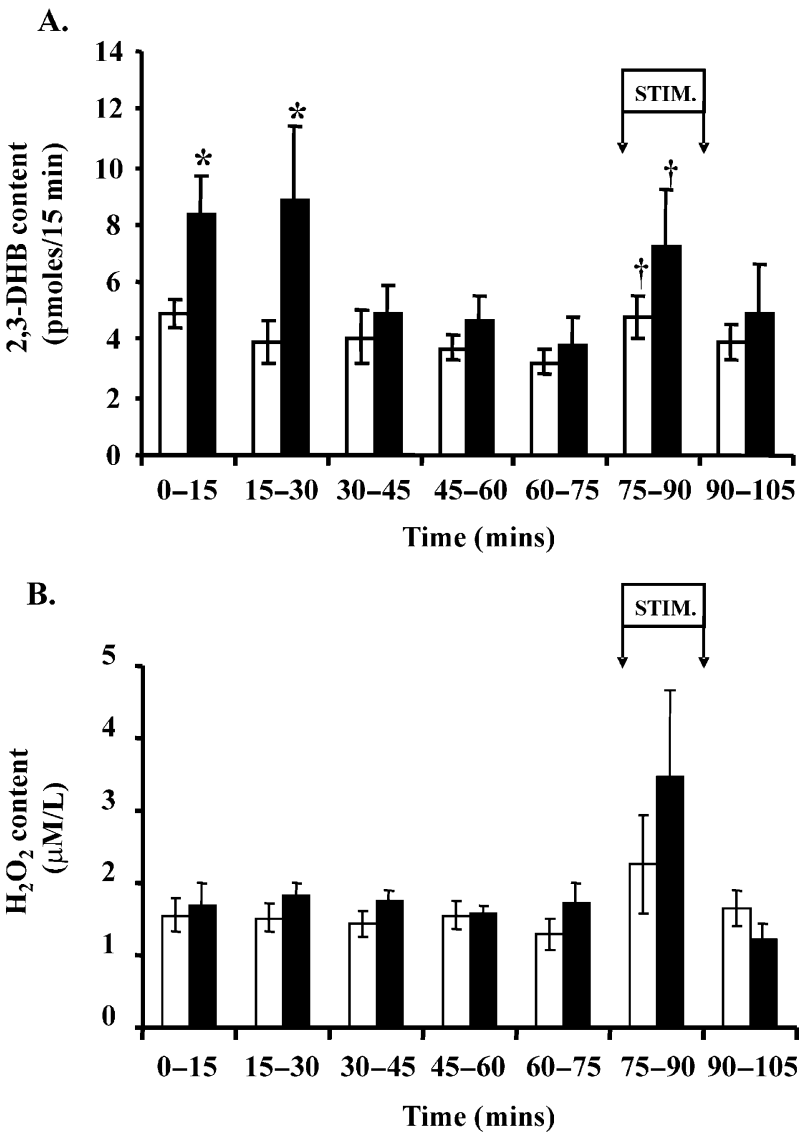

Fig. 4 2,3-DHB content (A) and hydrogen peroxide content (B) of microdialysates from the GTN muscles from adult ( $\square$ ) and old ( $\square$ ) mice. Muscles underwent 15-min periods of demanding contractile activity during the period shown. Data are shown as the mean \pm SEM. ${ }^{*} P<0.05$ compared with content in microdialysates from adult muscle at the same time point; $+P<0.05$ compared with microdialysates from the same group of mice at the previous time point.

with that in muscle from adult mice following an identical contraction protocol. The data obtained from each of the three approaches were consistent in indicating that contractile activity in muscle from old mice was not associated with an increased ROS generation or release in comparison with adult mice.

\section{ROS generation by isolated mitochondria}

Measurements of ROS generation by isolated mitochondria have previously been used to demonstrate an increased release of hydrogen peroxide by mitochondria associated with aging in different species (Perez-Campo et al., 1998; Capel et al., 2005) and in varying tissues of aging rodents (Cavazzoni et al., 1999). In skeletal muscle the amounts of hydrogen peroxide generated may depend upon the fiber type composition of the muscle studied (Capel et al., 2005) and the location of the mitochondria (Judge et al., 2005), but there is a general agreement that isolated mitochondria from old organisms release increased amounts of hydrogen peroxide deriving from superoxide formed by electron 'leakage' from the mitochondrial electron 

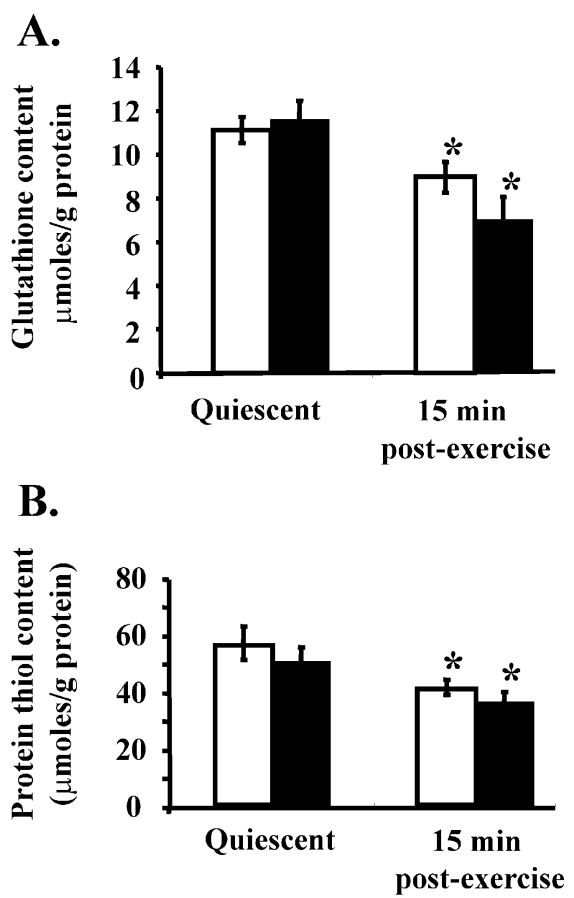

Fig. 5 Total glutathione content (A) and total protein thiol content (B) of GTN muscle from adult $(\square)$ and old ( $\square$ ) mice immediately prior to exercise (quiescent) and at 15 min post contractions. Data are shown as the mean \pm SEM. ${ }^{*} P<0.05$ compared with values prior to exercise for the same age of mice.

transport chain (Raha \& Robinson, 2000). The data reported here confirm the increased release of hydrogen peroxide by mitochondria isolated from the skeletal muscle of old mice compared with adult mice at rest (Fig. 2).

No current techniques allow a direct measurement of the ROS release from skeletal muscle mitochondria during or immediately following contractile activity since isolation of the mitochondria requires $1.5-2.0 \mathrm{~h}$ following removal of the muscle tissue. We reasoned that measurements of hydrogen peroxide generation by mitochondria isolated following the contraction protocol would indicate whether the contraction protocol had influenced the integrity (or fidelity) of the mitochondria or electron transport chain to a greater extent for old mice compared with adult animals. In both groups, the values obtained from the mitochondria isolated postexercise were significantly higher than those pre-exercise indicating that the period of contractile activity had influenced the ability of the mitochondria to regulate superoxide generation, but there were no differences between the final values from adult and old mice. Hence there is no evidence that contractile activity had a greater effect on generation of ROS by mitochondria in muscle from old mice compared with that from younger mice.

\section{Microdialysate analyses}

This study has utilized the microdialysis technique to evaluate relative rates of ROS generation by muscles of adult and old mice with and without a period of contractile activity. Previous attempts to investigate this area have used techniques that involved disruption of normal cellular structure (Bejma \& Ji, 1999) and hence are susceptible to potential artifact due to iron delocalization during the homogenization process (Halliwell \& Gutteridge, 1989). The microdialysis approach involves insertion of the probe into the interstitial space and monitoring of extracellular ROS. Although the microdialysis probe only provides direct access to the extracellular space, there is evidence that intracellular ROS directly affects some of the extracellular species. Thus previous data indicate that hydrogen peroxide and hydroxyl radical activity detected in the extracellular space reflects the rate of intracellular generation of hydrogen peroxide (Silveira et al., 2003; McArdle et al., 2004b) while NO is recognized to readily cross the plasma membrane (Demple, 2004).

The microdialysis studies indicated that the period of contractile activity increased ROS generation in adult mice leading to an increase in the extracellular superoxide and extracellular hydroxyl radical activity as previously reported (McArdle et al., 2001, 2004b), but the data reported here do not support the hypothesis that contractile activity leads to a greater increase of ROS generation in muscle of old mice. Our recent data have clarified that the placement of microdialysis probes in mouse GTN muscle causes a transient increase in ROS generation, but that levels stabilize within 45-60 min, after which time changes in ROS stimulated by physiological interventions can be resolved (Close et al., 2005). This protocol was followed in the current study.

The superoxide detected in microdialysates did not differ in the resting samples from old compared with adult mice. Superoxide levels were found to increase during contractile activity in the adult mice in agreement with previous studies (McArdle et al., 2001, 2004b), but no significant increase occurred during contractile activity in microdialysates from muscle of old mice. Previous data indicate that the superoxide detected in microdialysates does not originate from intracellular sites (McArdle et al., 2004b) and appears to be generated at the plasma membrane of the muscle fiber by a poorly characterized system (Pattwell \& Jackson, 2004). The data presented here appear to indicate that this system is not active in contracting muscle from old mice.

Total nitrate and nitrite content of the microdialysates, measured as an index of NO release into the interstitial fluid, showed no significant differences between adult and old animals although mean values were always lower in the microdialysates from old mice. No changes were seen for each group with contractile activity, although previous data have indicated that contractile activity increases NO release by skeletal muscle (Balon \& Nadler, 1994; Pattwell et al., 2004). However, numerous additional cell types (e.g. endothelial cells, smooth muscle cells) may contribute to the NO released into interstitial fluid and hence be detected in microdialyis measurements. NO released from these sources may therefore dilute the effect of any NO released from contracting skeletal muscle. NO release showed considerable variability between muscles from individual animals in common with some previous reports (Hirschfield et al., 2000). 
Microdialysates from quiescent GTN muscles of both adult and old mice contained $\sim 1.7 \mu \mathrm{M}$ hydrogen peroxide and the levels tended to increase in both adult and old mice during contractile activity although the changes were not significant (Fig. 4). An evaluation of the true concentration of dialytes in the muscle interstitial fluid is dependent upon the recovery across the microdialysis probe. Our unpublished data indicate that this is $12-15 \%$ for hydrogen peroxide with the microdialysis probes used here and thus true interstitial hydrogen peroxide concentrations are likely to be in the order of 10-15 $\mu \mathrm{M}$ at rest. Direct analyses of human blood have indicated hydrogen peroxide levels of $\sim 7 \mu \mathrm{m}$ (Deskur et al., 1998).

Hydroxyl radical activity in the muscle interstitial fluid of old mice (assessed by formation of 2,3-DHB from salicylate) was increased compared with adult mice during the first two baseline collection periods. Values declined prior to the beginning of the contraction protocol and during the final three baseline periods the values were not significantly different to those seen for adult mice. We interpret this to mean that the insertion of the microdialysis probe caused relatively greater trauma to the muscles in the old than in the adult mice since minor damage to tissues can cause release of iron leading to increased local generation of hydroxyl radicals (Halliwell \& Gutteridge, 1989). An increase in extracellular hydroxyl radical activity was seen during contractile activity in both adult and old mice with no significant differences between the two groups.

These data are therefore compatible with previous studies indicating an increase in the ROS detected in muscle interstitial space during contractile activity, but do not support the hypothesis that this generation is increased in muscle from old mice.

\section{Glutathione and protein thiol content}

The muscle glutathione and protein thiol contents were unchanged in old compared with adult mice at rest (Fig. 5). This is in agreement with some previously published papers (Bejma \& Ji, 1999) although the effect of age may be dependent upon the fiber type predominance of the specific muscle under study (Leeuwenburgh et al., 1994). The muscle glutathione and protein thiol contents in both old and adult mice were decreased by the period of contractile activity in agreement with some previous data (Ji et al., 1992; McArdle et al., 2001). Muscle from old mice showed no greater loss of glutathione or protein thiols than muscle from adult mice, such that after contractile activity the levels were not significantly different. The mechanisms underlying the decrease in muscle glutathione and protein thiol content that accompanies various forms of contractile activity are unclear, but many authors assume that the thiol groups are oxidized by reaction with ROS generated during activity (Ji et al., 1992; Sastre et al., 1992). In this case, the data presented here indicate that a similar level of oxidation of thiol groups occurs in muscle from old compared with adult mice during the contractile protocol used here.

The primary reason for monitoring force generation by the contracting mouse hind limb was to confirm maximal excitation of the hind limb muscles throughout the contraction period.
Although some previous data indicate that skeletal muscles of old mice display a substantial loss in their capacity to generate absolute force (Brooks \& Faulkner, 1988; McArdle et al., 2004a), a significant impairment in the force development of muscles in old mice was not observed. The plantar-flexor muscles of both adult and old mice generated maximum forces of over $2000 \mathrm{mN}$ and several factors may have contributed to our inability to find a significant difference in the maximum isometric force developed by the two age groups. These include (i) the inclusion of three muscles, GTN, plantaris and soleus muscles, each with different fiber lengths inserting into the Achilles tendon and (ii) the indirect activation by surface electrodes rather than direct activation through the nerve. Although the variance was greater for the plantar flexors than for the extensor digitorum longus muscle that has been studied previously (Brooks \& Faulkner, 1988; McArdle et al., 2004a), the mean values for force generation were reasonably stable and the data on a given preparation was stable over time. The difficulties arise in accurately assessing the specific force generated by such relatively large complex muscles. The contraction protocol produced a rapid loss of force generation by the plantar-flexor muscles of both adult and old mice with no difference between the two groups which demonstrates that our inability to find any putative enhancement of ROS generation in muscles of old mice was not due to a reduced activation of muscle in these animals.

Examination of the relative ROS generation induced by contractile activity in skeletal muscle of adult and old mice in vivo is inherently complex and all of the techniques used here have acknowledged drawbacks. Hence, for example, it is not possible to directly monitor hydrogen peroxide release from mitochondria during contractions of intact muscle, the microdialysis approach can only provide direct access to the extracellular space, and measurements of total muscle thiols may not provide a true reflection of site specific changes. Nevertheless in the current study, the concurrence of data from the three distinct approaches provides increased reassurance of the validity of the overall finding. Thus, we have obtained no evidence that ROS generation and activity is excessive in skeletal muscles of old mice at rest or during a demanding isometric contraction protocol. These data have important implications for understanding the involvement of skeletal muscle-derived ROS in aging-related oxidant damage to tissues and, if demonstrated to be applicable to humans, they support the view that exercise participation in elderly subjects is to be encouraged without any increased risk of oxidant damage to skeletal muscle.

\section{Experimental procedures}

\section{Mice}

The studies were carried out on 39 male and 47 female C57BI/ 6 mice, of which 42 were adult, aged 5-11 months, and 44 were old, aged 26-30 months. The mice were maintained under barrier conditions in a temperature-controlled environment and fed a commercial mouse chow (Teklad diet LM485) ad libitum. 
Each of the experimental procedures, including (i) insertion of the microdialysis probe, (ii) preparation for the contraction protocol and administration of the contraction protocol, and (iii) sampling from the probes, was carried out with the mouse under deep anesthesia. Mice were anesthetized with pentobarbitone sodium with an initial dose of $65 \mathrm{mg} / 100 \mathrm{~g}$ of body mass via an intraperitoneal injection. Supplemental doses were administered as required to maintain a depth of anesthesia sufficient to prevent response to tactile stimuli. Upon completion of an experiment on a given mouse, the mouse was euthanized by an overdose of the anesthetic and muscles were removed quickly for subsequent analyses.

\section{Measurement of extracellular ROS}

The superoxide anion content, hydrogen peroxide content, nitrate and nitrite content and hydroxyl radical activity in the interstitial fluid from quiescent muscles were obtained by sampling the extracellular space with microdialysis probes placed in the GTN muscles. Microdialysis probes (MAB 3.8.4, Metalant $A B$, Stockholm, Sweden) with a molecular weight cut-off of 35000 Da were placed into the GTN muscles of both limbs of anesthetized animals using a $22 \mathrm{G}$ plastic introducer. Four probes were placed into one (GTN) muscle and were either perfused with normal saline (for analysis of hydrogen peroxide and nitrate and nitrite), $20 \mathrm{~mm}$ salicylate in normal saline (for detection of hydroxyl radical activity; McArdle et al., 2004b) or $50 \mu \mathrm{M}$ cytochrome $\mathrm{c}$ in normal saline (for analysis of superoxide levels, McArdle et al., 2001) at a flow rate of $4 \mu \mathrm{L} \mathrm{min}{ }^{-1}$ and allowed to stabilize for $30 \mathrm{~min}$. Samples were collected from the probes over sequential 15-min periods.

\section{Contraction protocol}

Following collections of microdialysates from one GTN over five consecutive 15-min periods, the knee of the other hind limb was fixed to a base plate, the Achilles tendon was attached to a force transducer and the musculature of both hind limbs was stimulated to contract by surface electrodes placed around the upper limbs and the ankles to induce isometric contractions under in vivo conditions (McArdle et al., 2001). Fiber length was set at the optimum length for force production. Maximum isometric tetanic contractions were produced by square wave pulses of $0.2 \mathrm{~ms}$ duration, a voltage slightly greater than that required to produce a maximum twitch (usually $\sim 70 \mathrm{~V}$ ) and at a frequency of $100 \mathrm{~Hz}$ (Brooks \& Faulkner, 1988). Maximum isometric contractions were held for 500 ms with a contraction every $4 \mathrm{~s}$ for a total of 225 contractions during the 15 min of the contraction protocol. Following completion of the contraction protocol, microdialysis samples were collected for a further 15-min period.

\section{Collection of muscle samples for biochemical analysis}

Muscle samples were obtained from quiescent mice that were euthanized by overdose of anesthesia and the GTN muscles removed for biochemical analyses without undergoing the contraction protocol and from mice that were euthanized $15 \mathrm{~min}$ after the completion of the contraction protocol. These muscles were rapidly frozen in liquid nitrogen and stored at $-70^{\circ} \mathrm{C}$ until analyzed.

A further four groups of five mice were used to obtain muscle for isolation of mitochondria for measurement of ROS generation. All major muscles from the mouse hind limbs were rapidly removed from groups of euthanized adult and old mice prior to, and following, the contraction protocol and placed into cold mitochondria isolation buffer.

\section{Isolation of skeletal muscle mitochondria}

All procedures for mitochondrial isolation were conducted at $4{ }^{\circ} \mathrm{C}$. Mitochondria were isolated from skeletal muscle essentially as described by Lee et al. (1979). Briefly, rapidly excised muscles were transferred into Chappel Perry isolation buffer (100 mM KCl, 50 mM Tris- $\mathrm{HCl}, 5$ mm MgCl 2,1 mm EDTA, $1 \mathrm{~mm}$ ATP, $\mathrm{pH} 7.4)$, minced with scissors and incubated for 5 min with protease $\left(0.15 \mathrm{mg} \mathrm{mL}^{-1}\right.$ Nagarse) (Sigma, St. Louis, MO, USA). Muscles fragments were homogenized and the resulting homogenates were centrifuged at $600 \mathrm{~g}$ for $10 \mathrm{~min}$. The supernatants were decanted, filtered through gauze (Bellco Class Inc. Vineland, NJ, USA) and centrifuged at $14000 \mathrm{~g}$ for $10 \mathrm{~min}$. The resulting pellets were resuspended in washing buffer $(100 \mathrm{~mm} \mathrm{KCl}, 50 \mathrm{~mm}$ Tris- $\mathrm{HCl}, 1 \mathrm{~mm} \mathrm{MgCl}, 0.2 \mathrm{~mm}$ EDTA, $0.2 \mathrm{~mm}$ ATP, pH 7.4) supplemented with $0.5 \%$ bovine serum albumin (BSA) and centrifuged at $7000 \mathrm{~g}$ for $10 \mathrm{~min}$. The mitochondrial pellets were washed in buffer without BSA and centrifuged at $3500 \mathrm{~g}$ for $10 \mathrm{~min}$. The final mitochondrial pellets were resuspended in $200 \mu \mathrm{L}$ of $100 \mathrm{~mm} \mathrm{KCl}, 50 \mathrm{~mm}$ MOPS, pH 7.44, for measurement of hydrogen peroxide production. Using this isolation technique for skeletal muscle mitochondria and measuring respiration with a Clark electrode as described by Estabrook (1974), the respiratory control ratio (RCR) using substrates glutamate and malate was approximately 7.9 .

\section{Hydrogen peroxide production by isolated mitochondria}

Mitochondrial hydrogen peroxide release was measured using Amplex ${ }^{\mathrm{TM}}$ Red-horseradish peroxidase (Molecular Probes, Eugene, OR, USA) as previously described (Muller et al., 2004). This assay utilizes horseradish peroxidase (HRP) to catalyze the hydrogen peroxide-dependent oxidation of the nonfluorescent compound Amplex Red $(80 \mu \mathrm{M})$ to fluorescent resorufin red. The assay detects only hydrogen peroxide which has been released from the mitochondria as the size of the HRP restricts it from entering the mitochondria. CuZnSOD (Sigma) was added to convert any superoxide present into hydrogen peroxide, preventing interaction of the superoxide with the HRP directly. Briefly, $80 \mu \mathrm{M}$ Amplex ${ }^{\mathrm{TM}}$ Red reagent and $1 \mathrm{U} \mathrm{mL}^{-1}$ horseradish peroxidase (HRP) were added to the mitochondria (100 $\mu \mathrm{g}$ protein) or to 
the hydrogen peroxide standard solution in $100 \mu \mathrm{L}$ of reaction buffer: 50 mM MOPS, 100 mM KCl (pH 7.44) and incubated in Falcon 96 -well microplates in the dark at $30^{\circ} \mathrm{C}$. Fluorescence was followed at an excitation wavelength of $530 \mathrm{~nm}$ and an emission at $590 \mathrm{~nm}$ for $10 \mathrm{~min}$ in an automatic microplate reader equipped with a thermal-controlled compartment. The slope of the increase in fluorescence is converted to the rate of hydrogen peroxide production with a standard curve. The rates of hydrogen peroxide production were determined in the absence of substrate (State 1). Values were obtained from five mice per group.

\section{Analysis of microdialysates}

2,3-Dihydroxybenzoic acid (2,3-DHB) generated from hydroxyl radical reaction with salicylate in the microdialysis fluids was measured as an index of hydroxyl radical activity by HPLC with electrochemical detection as previously described (Pattwell et al., 2001). Reduction of cytochrome $c$ in the microdialysate was used as an index of superoxide anion radical concentration in microdialysates as previously described (McArdle et al., 2001). The total nitrate and nitrite content of microdialysates was measured as an index of total NO generation using a commercial fluorometric assay (Cayman Chemical Co., Ann Arbor, MI, USA) based on the method of Miles et al. (1995). The hydrogen peroxide content of microdialysates was measured using a modification of the method of Lei et al. (1998).

\section{Total glutathione and protein thiol content}

The automated glutathione recycling method described by Anderson (1996) was used to assess the total glutathione content of muscle samples, using a 96-well plate reader (Benchmark, Bio-Rad, Hemel Hempstead, UK). The protein thiol content of samples was analyzed by the method of Di Monte et al. (1984) adapted for use on a 96-well plate reader.

\section{Muscle total SOD activity}

Total muscle SOD activity was measured according to the method of Crapo et al. (1984).

\section{Muscle catalase activity}

Muscle homogenates were analysed for catalase activity by following the kinetic decomposition of hydrogen peroxide spectrophotometrically at $240 \mathrm{~nm}$ using the method described by Claiborne (1985).

\section{Statistical analyses}

All data are presented as mean \pm SEM. Statistical analyses for potential differences between groups were undertaken by ANOVA and where differences were indicated a modified (Bonferroni) $t$-test was applied.

\section{Acknowledgments}

This research was supported by the United States National Institutes on Aging (PO1, AG20591). The authors would like to thank Tatania Kostrominova, Cheryl Hassett and Carol Davis for advice and assistance in these studies.

\section{References}

Anderson ME (1996) Measurement of antioxidants: glutathione. In: Free Radicals, A Practical Approach (Punchard NA, Kelly FJ, eds). Oxford: IRL Press, pp. 213-226.

Balon TW, Nadler JL (1994) Nitric oxide release is present from incubated skeletal muscle preparations. J. Appl. Physiol. 77, 2519-2521.

Bejma J, Ji LL (1999) Aging and acute exercise enhance free radical generation in rat skeletal muscle. J. Appl. Physiol. 87, 465-470.

Brooks SV, Faulkner JA (1988) Contractile properties of skeletal muscles from young, adult and aged mice. J. Physiol. 404, 71-82.

Capel F, Buffiere C, Mirand PP, Mosoni L (2005) Differential variation of mitochondrial $\mathrm{H}_{2} \mathrm{O}_{2}$ release during aging in oxidative and glycolytic muscle in rats. Mech. Ageing Dev. 125, 367-373.

Cavazzoni M, Barogi S, Baracca A, Parenti Castelli G, Lenaz G (1999) The effect of aging and an oxidative stress on peroxide levels and the mitochondrial membrane potential in isolated rat hepatocytes. FEBS Lett. 449, 53-56.

Cho CG, Kim HJ, Chung SW, Jung KJ, Shim KH, Yu BP, Yodoi J, Chung HY (2003) Modulation of glutathione and thioredoxin systems by calorie restriction during the aging process. Exp. Gerontol. 38, 539-548.

Claiborne A (1985) Catalase activity. In: CRC Handbook of Methods for Oxygen Radical Research (Greenwald RA, ed.). Boca Raton, FL: CRC Press, pp. 283-284.

Close GC, Ashton T, McArdle A, Jackson MJ (2005) Microdialysis studies of extracellular reactive oxygen species in skeletal muscle: factors influencing the reduction of cytochrome $\mathrm{c}$ and hydroxylation of salicylate. Free Rad. Biol. Med. 39, 1460-1467.

Crapo JD, McCord JM, Fridovich I (1984) Preparation and assay of superoxide dismutases. Methods Enzymol. 105, 382-393.

Davies KJA, Quintanilla AT, Brooks GA, Packer L (1982) Free radicals and tissue damage produced by exercise. Biochem. Biophys. Res. Comm. 107, 1198-1205.

Demple B (2004) Protection from the dark side of NO: signaling and cellular defenses against nitric oxide toxicity. IUBMB Life 56, 5964.

Deskur E, Przywarska I, Dylewicz P, Szczesniak L, Rychlewski T, Wilk M, Wysocki H (1998) Exercise-induced increase in hydrogen peroxide plasma levels is diminished by endurance training after myocardial infarction. Int. J. Cardiol. 67, 219-224.

Di Monte D, Bellomo G, Thor H, Nicotera P, Orrenius S (1984) Menadioneinduced cytotoxicity is associated with protein thiol oxidation and alteration in intracellular $\mathrm{Ca}^{2+}$ homeostasis. Arch. Biochem. Biophys. 235, 343-350.

Dillard CJ, Litov RE, Savin WM, Dumelin EE, Tappel AL (1978) Effects of exercise, vitamin $E$, and ozone on pulmonary function and lipid peroxidation. J. Appl. Physiol. 45, 927-932.

Estabrook RW (1974) Mitochondrial respiratory control and the polarographic measurement of ADP: O ratio. Methods Enzymol. 10, 41-47.

Halliwell B, Gutteridge JMC (1989) Free Radicals in Biology and Medicine. Oxford: Oxford University Press.

Hansford RG (1983) Bioenergetics in aging. Biochim. Biophys. Acta 726, 41-80.

Hirschfield W, Moody MR, O’Brien WE, Gregg AR, Bryan RM Jr. (2000) Nitric oxide release and contractile properties of skeletal muscles 
from mice deficient in type III NOS. Am J. Physiol. Regul. Integr. Comp. Physiol. 278, R95-R100.

Jackson MJ, Edwards RHT, Symons MCR (1985) Electron spin resonance studies of intact mammalian skeletal muscle. Biochim. Biophys. Acta 847, 185-190.

Javesghani D, Magder SA, Barreiro E, Quinn MT, Hussain SN (2002) Molecular characterization of a superoxide-generating $\mathrm{NAD}(\mathrm{P}) \mathrm{H}$ oxidase in the ventilatory muscles. Am. J. Respir. Crit. Care Med. 165, $412-418$.

Ji LL, Fu R, Mitchell EW (1992) Glutathione and antioxidant enzymes in skeletal muscle: effects of fiber type and exercise intensity. J. Appl. Physiol. 73, 1854-1859.

Judge S, Jang YM, Smith A, Hagen T, Leewenburgh C (2005) Ageassociated increases in oxidative stress and antioxidant enzyme activities in cardiac interfibrillar mitochnondria: implications for the mitochondrial theory of aging. FASEB J. 19, 419-421.

Lee CP, Martens ME, Jankulovska L, Neymark MA (1979) Defective oxidative metabolism of myodystrophic skeletal muscle mitochondria. Muscle Nerve 2, 340-348.

Leeuwenburgh C, Fiebig R, Chandwaney R, Ji LL (1994) Aging and exercise training in skeletal muscle: responses of glutathione and antioxidant enzyme systems. Am. J. Physiol. 267, R439-R445.

Lei $\mathrm{B}$, Adachi N, Arai T (1998) Measurement of the extracellular $\mathrm{H}_{2} \mathrm{O}_{2}$ in the brain by microdialysis. Brain Res. Brain Res. Protoc. 3, 33-36.

McArdle A, Jackson MJ (2000) Exercise, oxidative stress and ageing. J. Anat. 197, 539-541.

McArdle A, Pattwell D, Vasilaki A, Griffiths RD, Jackson MJ (2001) Contractile activity-induced oxidative stress: cellular origin and adaptive responses. Am. J. Physiol. Cell Physiol. 280, C621-C627.

McArdle A, Dillmann WH, Mestril R., Faulkner JA, Jackson MJ (2004a) Overexpression of HSP7O in mouse skeletal muscle protects against muscle damage and age-related muscle dysfunction. FASEB J. 18, 355-357.

McArdle A, Van Der Meulen J, Close GL, Pattwell D, Van Remmen H, Huang $T T$, Richardson AG, Epstein CJ, Faulkner JA, Jackson MJ (2004b) The role of mitochondrial superoxide dismutase in contractioninduced generation of reactive oxygen species in skeletal muscle extracellular space. Am. J. Physiol. Cell Physiol. 286, C1152-C1158.

Melov S, Shoffner JM, Kaufman A, Wallace DC (1995) Marked increase in the number and variety of mitochondrial DNA rearrangements in aging human skeletal muscle. Nucl. Acids Res. 23, 41224126.

Miles AM, Chen Y, Owens MW, Grisham MB (1995) Fluorimetric determination of nitric oxide. Methods 7, 40-47.

Muller FL, Liu Y, Van Remmen H (2004) Complex III releases superoxide to both sides of the inner mitochondrial membrane. J. Biol. Chem. 279, 49064-49073.

Nohl $H$ (1993) Involvement of free radicals in ageing: a consequence or cause of senescence. Br. Med. Bull. 49, 653-667.

Pattwell DM, Jackson MJ (2004) Contraction-induced oxidants as mediators of adaptation and damage in skeletal muscle. Exerc. Sport Sci. Rev. 32, 14-18.

Pattwell D, McArdle A, Griffiths RD, Jackson MJ (2001) Measurement of free radical production by in vivo microdialysis during ischemia/ reperfusion injury to skeletal muscle. Free Rad. Biol. Med. 30, 979985.

Pattwell DM, McArdle A, Morgan JE, Partridge TA, Jackson MJ (2004) Release of reactive oxygen and nitrogen species from contracting skeletal muscle cells. Free Rad. Biol. Med. 37, 1064-1072.

Perez-Campo R., Lopez-Torres M, Cadenas S, Rojas C, Barja G (1998) The rate of free radical production as a determinant of the rate of aging: evidence from the comparative approach. J. Comp Physiol. [B] 168, 149-158.

Porter MM, Vandervoort AA, Lexell J (1995) Aging of human muscle: structure, function and adaptability. Scand. J. Med. Sci. Sports 5, 129-142.

Raha S, Robinson BH (2000) Mitochondria, oxygen free radicals, disease and ageing. Trends Biochem. Sci. 25, 502-508.

Rasmussen UF, Krustup P, Kjaer M, Rasmussen HN (2003) Experimental evidence against the mitochondrial theory of aging: a study of isolated human skeletal muscle mitochondria. Exp. Gerontol. 38, 877-886.

Reid MB, Shoji T, Moody MR, Entman ML (1992) Reactive oxygen in skeletal muscle. II. Extracellular release of free radicals. J. Appl. Physiol. 75, 1805-1809.

Rembert V, Boirie Y, Bedu M, Hocquette JF, RitZ. P, Morio J (2004) Muscle fat oxidative capacity is not impaired by age, but by physical inactivity: association with insulin sensitivity. FASEB J. 18, 737-739.

Sastre J, Asensi M, Gasco E, Pallardo FV, Ferrero JA, Furukawa T, Vina J (1992) Exhaustive physical exercise causes oxidation of glutathione status in blood: prevention by antioxidant administration. Am. J. Physiol. 263, R992-R995.

Schoneich C (1999) Reactive oxygen species and biological aging: a mechanistic approach. Exp. Gerontol. 34, 19-34.

Silveira LR, Pereira-Da-Silva L, Juel C, Hellsten Y (2003) Formation of hydrogen peroxide and nitric oxide in rat skeletal muscle cells during contractions. Free Rad. Biol. Med. 35, 455-464.

Stio M, lantomasi T, Favilli F, Marraccini P, Lunghi B, Vincenzini MT, Treves C (1994) Glutathione metabolism in heart and liver of the aging rat. Biochem. Cell Biol. 72, 58-61.

Wang H, Liu H, Liu RM (2003) Gender difference in glutathione metabolism during aging in mice. Exp. Gerontol. 38, 507-517. 